Furman University

Furman University Scholar Exchange

Winter 3-2019

\title{
The Molecular Education and Research Consortium in Undergraduate computational chemistRY (MERCURY): Twenty Years of Exceptional Success Supporting Undergraduate Research and Inclusive Excellence
}

George C. Shields

Furman University

Follow this and additional works at: https://scholarexchange.furman.edu/chm-citations

\section{Recommended Citation}

Shields, George C., "The Molecular Education and Research Consortium in Undergraduate computational chemistRY (MERCURY): Twenty Years of Exceptional Success Supporting Undergraduate Research and Inclusive Excellence" (2019). Chemistry Department Faculty Citations. 571.

https://scholarexchange.furman.edu/chm-citations/571

This Citation is made available online by Chemistry, part of the Furman University Scholar Exchange (FUSE). It has been accepted for inclusion in Chemistry Department Faculty Citations by an authorized FUSE administrator. For terms of use, please refer to the FUSE Institutional Repository Guidelines. For more information, please contact scholarexchange@furman.edu. 


\section{The Molecular Education and Research Consortium in Undergraduate Computational Chemistry (MERCURY): Twenty Years of Exceptional Success Supporting Undergraduate Research and Inclusive Excellence}

George C. Shields, Furman University

\begin{abstract}
The author discusses the history of the Molecular Education and Research Consortium in Undergraduate Computational Chemistry (MERCURY), which has made significant contributions benefiting science faculty and undergraduates. The peer review publication rate of 1.7 for MERCURY faculty is 3.4 times the average rate for physical science faculty at primarily undergraduate institutions. Since 2001, 888 students have worked on research projects; 75 percent of them have come from underrepresented populations, such as female students or students of color. Approximately half of all graduates have pursued advanced degrees in STEM fields; two-thirds of this group have been female and/or students of color. More than 1,600 people have attended the 18 MERCURY conferences that have hosted 111 speakers, including 61 who were faculty members of color or female.
\end{abstract}

Keywords: chemistry, consortium, diversity, high-impact practices, MERCURY, undergraduate research

doi: 10.18833/spur/3/2/1

The academic year 2019-2020 is the 20th anniversary of the founding of the Molecular Education and Research Consortium in Undergraduate Computational Chemistry (MERCURY). The intellectual focus of the consortium is computational chemistry. The research projects of the 27 MERCURY faculty utilize computational tools to solve significant problems in atmospheric, biological, inorganic, materials, organic, and physical chemistry. MERCURY students are naturally drawn to these computer-based projects and often become involved in research in the first and second years of their undergraduate careers. Computational chemistry projects, by their very nature, are conducive to meaningful undergraduate participation because they build upon and reinforce most, if not all, of the chemistry, biology, and physics courses required for most undergraduate science concentrations. Students learn how to use computers just like they learn to use any scientific instrument. With close faculty mentoring, they quickly become highly skilled at both using sophisticated research-quality software tools and understanding the results. The research training provided at MERCURY institutions is ideally suited to the undergraduate environment for the following reasons:

- The research involves important projects, the results of which will be of interest to many chemists, and yet the computational methodology is not too complex for the average undergraduate student, given the highly mentored nature of the research groups.

- Each project can easily be subdivided into units that can be completed by individual students during a summer of undergraduate research.

- With proper supervision, even first-year science majors can become successfully involved in the research.

The use of computational chemistry in postbaccalaureate graduate and industrial programs has grown enormously in the last two decades. A research background in computational chemistry will be useful no matter what field of science students choose after their undergraduate studies. The consortium is most productive when students work multiple summers in the labs, and the program strives for consistency so that third- and fourth-year students with several years of research experience can help train the younger students. 


\section{Project Origins, 1999-2001}

The initial idea stemmed from a failed Howard Hughes Medical Institute (HHMI) proposal, when the author chaired the chemistry department at Hamilton College (NY). Part of the proposal was devoted to integration of computational science across the science curriculum. This led to creating a consortium of like-minded computational chemists at primarily undergraduate institutions (PUIs) that would work to integrate computational chemistry across participating colleges and universities. A particular effort was made to include female faculty and faculty of color from other colleges in the Northeast, as it was believed that they would benefit greatly from a networking cohort of like-minded investigators. During the academic year 1999-2000, Carol Parish (Hobart and William Smith Colleges), Jeffery Greathouse (St. Lawrence University), Maria Gomez (Vassar College), Ramona Taylor (Holy Cross University), and Martha Reynolds (Colgate University) were contacted. The author planned to undertake the majority of the writing and organizing for the proposal. A grant proposal for acquisition of high-performance computers for the Northeastern Undergraduate Research Chemistry Consortium was submitted to the National Science Foundation Major Research Instrumentation (NSF MRI) program in January 2000, and it was not funded. Although reviewers liked the concept of an interinstitutional computer consortium with a system administrator, they believed the $\$ 2$ million cost was too high and that a cluster of computers should be built instead of buying a SGI Origin. There also were concerns that the collaborators had not yet established themselves as major players in the computational field.

To address these issues, further research was done on the desired computer system. It was eventually decided that, because of the myriad different software in use at the various institutions, the proposed SGI technology was, in fact, what was needed. Gene Tobin, then president of Hamilton College, felt that this was a good investment for the sciences and agreed to matching funds of $\$ 400,000$. Another investigator, Marc Zimmer (Connecticut College), was invited to join the consortium. His suggestions greatly improved the proposal. In addition, Dreyfus postdoctoral associate Steven Feldgus joined the author's group and made very valuable contributions to the proposal. The author visited Hobart and William Smith, St. Lawrence, Vassar, Holy Cross, and Connecticut College to give seminars on his work and talk about the benefits of forming this consortium. These visits were followed by invitations to hold seminars at institutions in the consortium. It was decided that, for the consortium proposal to have the best chance for success, each faculty member needed to be as productive as possible. Thus, there was a significant increase in the number of individual grant proposals and papers submitted prior to the second NSF MRI proposal submission.
The second submission, in February 2001, addressed all prior concerns. Reviewers were impressed with the formation of a consortium that had already increased research productivity with undergraduate research groups and recognized that mentoring would be an important part of future success. Distinctive features of the funded proposal, NSF MRI award CHE 0116435, included the following:

- Hamilton College pledged $\$ 400,000$ in matching funds, including $\$ 380,000$ toward the high-performance SGI computers and $\$ 20,000$ to support the annual conferences for three years. NSF viewed the matching funds as significant.

- Each institution pledged at least $\$ 35,000$ for local graphics workstations (SGI Octanes).

- In the final proposal, the matching funds totaled $\$ 615,000$, and $\$ 780,220$ was requested from NSF.

- The total project cost, including matching funds, was approximately $\$ 1.5$ million.

- A system administrator and a research support specialist were hired at Hamilton College.

- Hamilton College agreed to pick up the salary of the system administrator at the end of the three-year grant period.

- High-performance computers were located at Hamilton College.

- An annual conference in undergraduate computational chemistry was instituted in summer 2002.

The makeup of the consortium, with four of seven faculty members who were female and two faculty members of color, helped convince the NSF review panel that the proposed program would have a positive effect on the education of students of color. The hardware and system administrator requests were viewed as essential, and the productivity of the collaborators was noted. One panel member who also had reviewed the first proposal was impressed by the fact that the consortium was not daunted by the lack of funding for the initial proposal and spent the next year working to improve relationships through personal visits, seminar presentations, and exchange of ideas for future collaborations (Shields 2002).

\section{First Grant Period, 2001-2004}

The first conference of the consortium was held on July 21-23, 2002, at Hamilton College in Clinton, NY. From the beginning, the conference was national in scope. Faculty and undergraduates from all institutions were invited to participate, and there were 70 attendees -35 undergraduates and 35 faculty - at the first MERCURY conference. Forty percent of all participants, including the speakers, were female or faculty of color. The seven keynote speakers at the first conference included Chris Cramer (University of Minnesota), who spoke on modeling drug bioavailability, organic structure and reactivity, and other solvation-dependent phenomena; Heather Carlson 
(University of Michigan), who discussed protein flexibility and drug design; Harold Scheraga (Cornell University), who lectured on prediction of protein structure; Wilma Olson (Rutgers University), who discussed DNA structure and function; Barbara Garrison (Penn State University), who spoke about modeling fast deposition of energy at surfaces with ion beams and lasers; Michael Gilson (University of Maryland-College Park), who talked about molecular recognition; and Roberto Gomperts (SGI), who provided tips on how to use the Gaussian98 software code for large-scale ab initio calculations. Guests spoke for an hour, using their talks to interest students in a problem, teach methods, and present some applications. Speakers were encouraged to talk about their graduate school programs or their work in industry.

The second conference in summer 2003 had 65 participants, and 42 percent of participants and speakers were female or persons of color. At the third conference in summer 2004, there were 70 participants. Of the speakers, 57 percent were women or faculty of color, and overall 53 percent of participants were women or persons of color. Forty undergraduates presented posters at the second conference and also at the third conference. Faculty and students attended from as far away as California, Texas, and Canada.

Key features of the consortium that have continued to this day include an initial meeting, on the first night of the conference, of all MERCURY faculty to discuss issues of importance-such as sharing of computational resources, maintaining productive undergraduate research programs, and balancing demands on faculty members at PUIs; social events for faculty and students; a poster session at which undergraduates make presentations and faculty ask questions and make suggestions; and a dinner for MERCURY faculty and the invited speakers. The poster session is particularly interesting as it is a conference at which all students - ranging from high school students, to first-year students, to recent graduates - are immersed in an environment in which all faculty members and speakers are experts in some facet of computational chemistry. As Ken Jordan of the University of Pittsburgh stated when he was a speaker at the 2003 conference, it was like "a Gordon Research Conference for undergraduates."

During that first three-year grant period, the seven MERCURY faculty worked with 110 undergraduates, who were trained to run quantum chemical and molecular dynamics simulations in biochemistry, environmental chemistry, and inorganic and organic chemistry. In total, 44 peerreviewed papers were published in the scientific literature, or 2.1 papers per year per faculty member and 4.2 times the average publication rate in the physical sciences at PUIs (0.5 pubs/faculty/year; Research Corporation 2001). Three of the research groups consisted of at least 22 percent African American or Hispanic students. Student researchers mentored by MERCURY faculty won one Rhodes, five Fulbright, one Gates Cambridge, and six Goldwater Scholarships during this three-year period and matriculated to a variety of graduate institutions, including Columbia University, Oxford University, Yale University, the University of Wisconsin, and the University of Minnesota. Furthermore, in the four years since the consortium had been established, the number of external grant awards received by faculty had more than tripled. Altogether more than $\$ 4$ million was raised to support computational chemistry research involving undergraduate students. The bulk of this funding was used to provide summer stipends that allowed students to immerse themselves in full-time research. The high rate of success in recruiting and retaining students, particularly those from underrepresented groups, was attributed to this funding.

After submission of the final activities report, Joan Frye, the MRI program director at NSF during the first proposal period, stated that the MERCURY program had had the best results of an undergraduate MRI during the prior five-year period. She planned to use the project and final report during the next external peer review of the NSF MRI program. See Figures 1 and 2.

\section{Second Grant Period, 2005-2008}

The second NSF MRI proposal, submitted in early 2005, was for acquisition of a Linux cluster for the MERCURY program. NSF MRI award CHE 0521063 was for $\$ 100,000$. The Linux cluster was a cost-efficient addition to the MERCURY resources. Greathouse, Taylor, and Reynolds left the consortium before the third proposal. Parish and Gomez moved to the University of Richmond and Mount Holyoke College, respectively, in recognition of their success as teacher-scholars. Zimmer and Shields received endowed professorships at their institutions. Maria Nagan (Truman State University), Tricia Shepherd (Westminster College, UT), Wingfield Glassey (Hobart and William Smith Colleges), and Glênisson de Oliveira (Rhode Island College) were added to the consortium. Added later were Mauricio Cafiero (Rhodes College), Eric Patterson (Truman State), Kelling Donald (University of Richmond) and Daqing Gao (Queensborough Community College, NY), during the 2005-2008 grant period, and all four were part of the third grant proposal, submitted in 2008. For each successive grant proposal, a letter was sent to the president, provost, or dean at each new institution, with an invitation for the faculty member to join the consortium and a request for institutional support for local computer graphics as well as travel to the annual meeting, so that students and faculty might receive the networking and mentoring benefits of the consortium. Request for travel support for each new member has continued. This was critical as the consortium expanded to colleges and universities with fewer resources than those of the original group from the Northeast. There 
FIGURE 1. SGI Origin 300, the First MERCURY High-Performance Computer (Purchased in 2001)

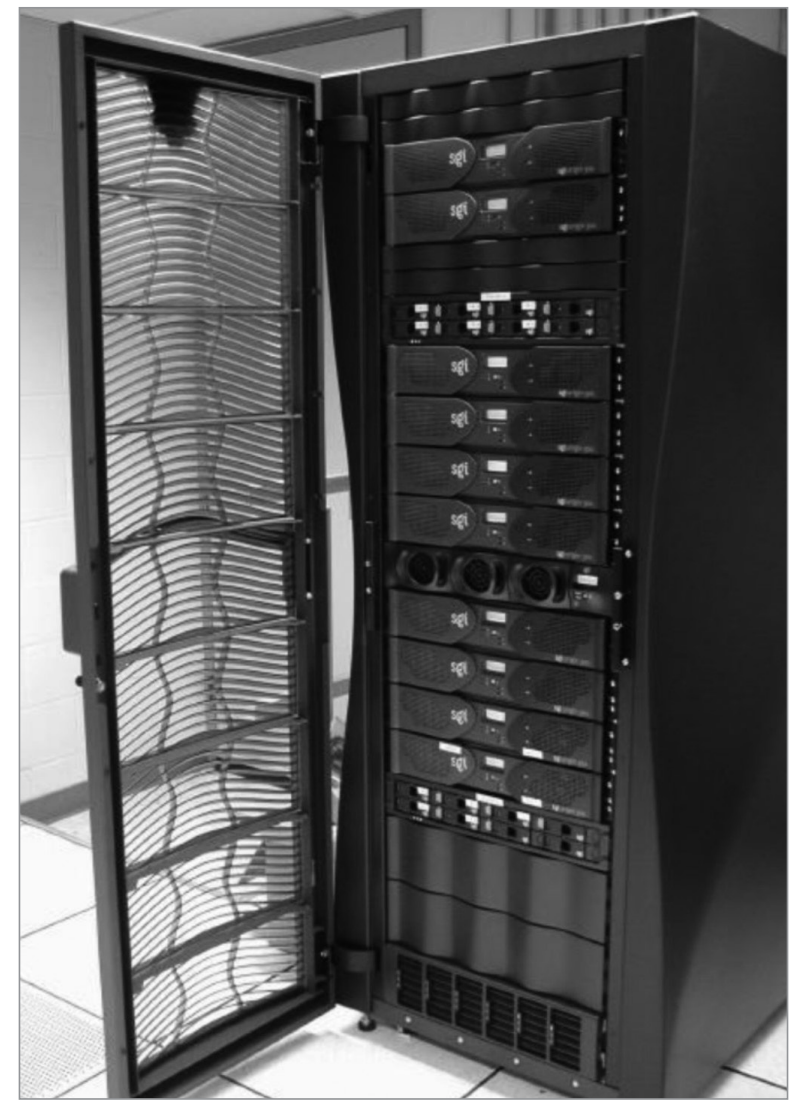

Note: The SGI Origin 300 consisted of one 8-processor unit with 4 GB of RAM and a 72-GB hard drive, and one 32-processor unit with $32 \mathrm{~GB}$ of RAM and more than $1 \mathrm{~TB}$ of disk space.

were no fees for MERCURY faculty and their students to attend the conference; this was supported using other funds (Hamilton matching grant funds and later administrative funds). There was a modest fee for faculty and students attending from non-MERCURY institutions. To acclimate new and interested faculty to the culture of the consortium, they were sent copies of prior NSF proposals and reports that reflected the strong commitment of the MERCURY group to undergraduate research for development of scientific research skills in students and a particular engagement with diversity and inclusion.

Overall, during the 2005-2008 grant period, the 12 MERCURY faculty worked with 140 undergraduate students, 13 high school students, 7 high school teachers, and 6 senior scientists. Of the 140 undergraduates, 89 were female, 14 were Asian, 13 were black or African American, and 12 were Hispanic or Latinx. A total of 101 undergraduates were female and/or students of color, which constituted 72 percent of the undergraduates trained in the labs. The MERCURY principal investigators published 47 publications, or
FIGURE 2. Keynote Speakers at the Second MERCURY Conference (2003) at Hamilton College

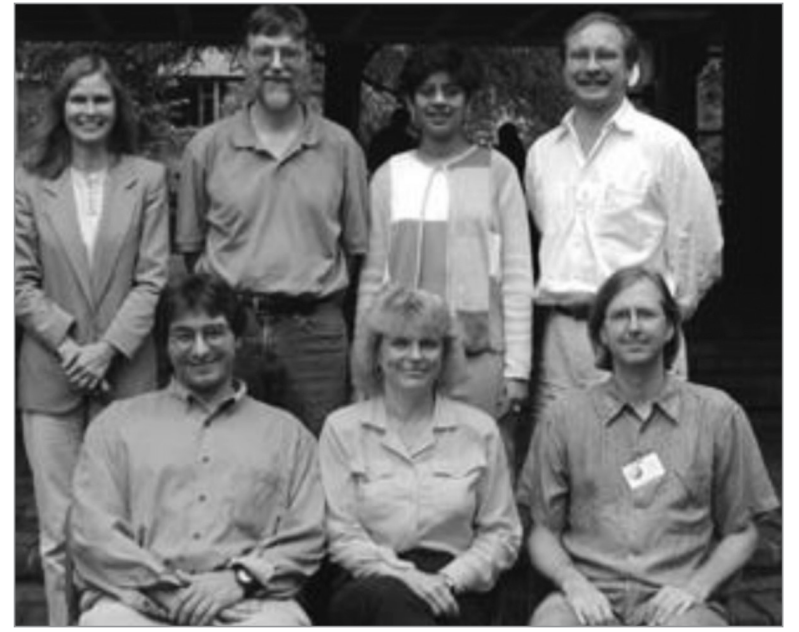

Back row, left to right: Jane S. Murray (University of New Orleans), Ken Jordan (University of Pittsburgh), Nita Sahai (University of Wisconsin), Kennie Merz (Penn State University). Front row, left to right: Darrin York (University of Minnesota), Anna Chaka (National Institute of Standards and Technology, MD), Carlos Simmerling (Stony Brook University-SUNY)

1.8 publications per faculty member per year (7 principal investigators were in the consortium for three years, and 5 were in the consortium for one year). This was 3.6 times the national average, as documented by Research Corporation (2001). Students won 20 national or international awards, including Goldwater and Fulbright Scholarships.

In summer 2005, between grants, the fourth annual MERCURY conference was held. An interesting aspect of these annual conferences is that the mentoring that occurs helps the most motivated teacher-scholars maintain or upgrade their research activities, whereas the least motivated often decide to leave the consortium before the next grant period (although some faculty leave academia to work at national labs or in industry, where they conduct research full time). There is discussion of problems needing innovative solutions, such as how to use early introduction to research to capture student interest and inspire more students to continue in science (Shields, Gajdosik-Nivens, and Ness 2017) and how to work with colleagues to promote an active research culture throughout the department (Kinnel et al. 2013). The fifth annual MERCURY conference in undergraduate computational chemistry was hosted in summer 2006, with 67 participants. The sixth annual MERCURY conference in summer 2007 had 86 participants; in summer 2008, the seventh annual conference had 98. From 2005 to 2008, more than 75 percent of the participants were undergraduates or high school students, and more than 50 percent of the speakers and 50 percent of the participants were women or faculty of color. 


\section{Third Grant Period, 2008-2011}

The third NSF MRI grant (CHE 0821581), in 2008, awarded $\$ 229,000$ for acquisition of a high-performance computer. Glassey and Gao left the group, and Becky Eggimann of Wheaton College joined the other 10 investigators. The author took a new position as founding dean of the college of science and technology at Armstrong Atlantic State University, and the new SGI Altix 450 was installed in Savannah. The two older Origin 300s and two Linux Beowulf clusters remained at Hamilton College until they were decommissioned. Annual conferences continued at Hamilton in 2009 and 2010, averaging 90 participants. Hamilton was very generous about funding the first nine summer conferences. The combination of different resources allowed the MERCURY consortium to run quantum calculations including electron correlation, such as $\operatorname{CCSD}(\mathrm{T})$, which required high memory (and thus SGI computers), and molecular dynamics calculations, which required less memory but many more processors (Linux clusters). The 11 investigators worked with 3 other senior personnel, 3 postdoctoral associates, 78 undergraduates, 11 high school teachers, and 6 high school students on research projects during the 2008-2009 academic year. Twenty-six publications were produced, or 2.3 per investigator.

During the second year of the grant, 2009-2010, de Oliveira left, and Adam Van Wynsberghe, who had taken the author's position at Hamilton College, and Clifford Padgett of Armstrong brought the consortium total to a dozen researchers. Over the three years of the grant period, the 197 personnel included 3 other senior researchers/ technicians, 5 postdoctoral associates (1 Asian female, 1 black female, and 1 black male), 165 undergraduates, 3 high school students, 11 precollege teachers, and 1 postbaccalaureate fellow. Of the 165 undergraduates, 92 were female, 26 were Asian, 21 were black, and 9 were Hispanic/Latinx. Of the 92 females, 14 were Asian, 13 were black, and 2 were Hispanic/Latina. An additional 36 papers were published over the last two years of the grant period, averaging 1.8 papers/faculty/year, more than three times the average rate at PUIs (Research Corporation 2001).

In summer 2010, the author moved to Bucknell University to serve as dean of arts and sciences, and the SGI Altix was moved from Savannah to Lewisburg (PA). The last conference at Hamilton was in summer 2010, and the 10th conference and first one at Bucknell was held in 2011. There were more than 800 attendees at the first 10 MERCURY conferences, with 63 speakers, 32 of whom had been female or faculty of color. See Figure 3.

\section{Fourth Grant Period, 2012-2015}

At the start of 2012, the MERCURY consortium consisted of Cafiero, Donald, Eggimann, Gomez, Nagan,

\section{FIGURE 3. Shields Research Group in 2009}

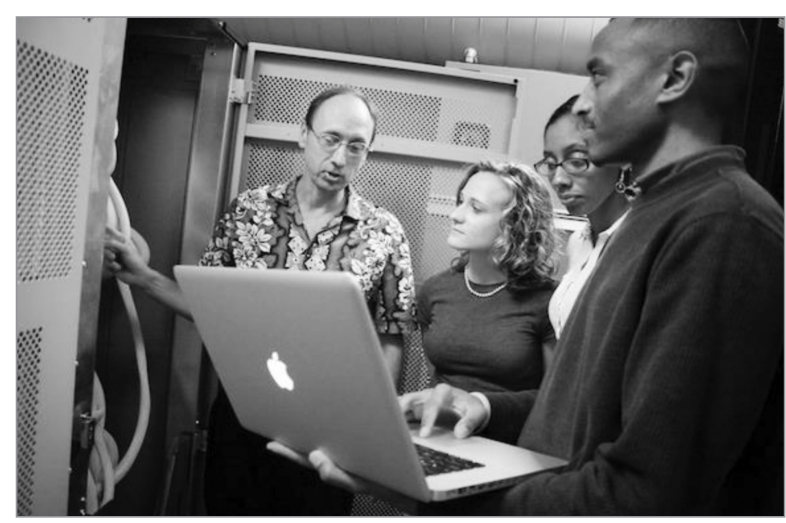

From left: George Shields, Amber Kay Palmer, Kaye Archer, and Berhane Temelso, with the SGI Altix 450 at then-Armstrong Atlantic State University.

Padgett, Parish, Patterson, Shepherd, Shields, Van Wynsberghe, and Zimmer. The next NSF MRI grant proposal saw the addition of Kelly Anderson (Roanoke College), Sudeep Bhattacharyay and Jim Phillips (both University of Wisconsin-Eau Claire), Aimée Tomlinson (University of North Georgia), and Daqing Gao, who rejoined the consortium after moving to Central State University. This brought the number to 17 investigators at PUIs. The intent of this fourth proposal was to make the most cost-efficient addition to MERCURY resources, while planning for the eventual decommission of the resources bought during the first two grant periods (CHE 0116435 and CHE 0521063) and housed at Hamilton College. The grant, award CHE 1229354 , funded for $\$ 200,000$, allowed purchase of a large Linux cluster. Computers become faster, more capable, and less expensive over time. By 2008, recent advances in multicore processing and fast InfiniBand interconnects and the massive drop in the cost of RAM made the unique capabilities of the SGI Altix machines readily available in Linux clusters at dramatically lower cost. For $\$ 200,000$, the system cost less than the SGI Altix yet had roughly 8 teraFLOPS (TF) of processing power, compared to $1 \mathrm{TF}$ for the SGI Altix.

Operations and maintenance of the high-performance computers were primarily handled by Steve Young, who was hired at Hamilton College in 2004, and Berhane Temelso, who started as a postdoctoral associate at Armstrong in 2011, and worked with the author as a research scientist at Bucknell and Furman until 2018. Young and Temelso worked together, combining the system administration knowledge of Young with the computational software capabilities of Temelso to enhance the ability of MERCURY system users to run their particular simulations as efficiently as possible. Support also was provided by the informational technology offices at the various institutions. 
During the 2012-2013 academic year, the 17 MERCURY investigators worked with 90 undergraduate students, 6 high school students, 4 postdoctoral fellows, and 2 technicians. More than 75 percent of the students were female and/or from underrepresented groups. During the 2013-2014 academic year, the 17 MERCURY investigators worked with 98 undergraduate students, 8 high school students, 5 postdoctoral fellows, and 2 technicians. Over 75 percent of the students were female and/or from underrepresented groups. During the 2014-2015 academic year, the 17 MERCURY investigators worked with 119 undergraduate students, 16 high school students, 4 postdoctoral fellows, 1 staff research scientist, and 2 technicians. Half of the undergraduate researchers were female (60), 21 were Asian Americans (16 female), 11 were Hispanic/ Latinx (4 female), 20 were black (6 female), and 1 was a Pacific Islander (female). Thus 53 students, or 44 percent, were from underrepresented groups. Without double counting females who belonged to these underrepresented groups, 86 of the 119 students, or 72 percent, were female and/or from underrepresented groups.

Overall, during the three-year period of this grant, the 17 MERCURY investigators worked with 200 undergraduates, and more than 75 percent of them were female and/ or from underrepresented groups. In addition, 16 high school students, 2 postbaccalaureate alumni, 2 technicians, 4 postdoctoral researchers, and 1 staff research scientist worked with the MERCURY investigators. Seventy-nine peer-reviewed papers were published that were coauthored by faculty and undergraduate students. This peer-reviewed publication rate was 1.5 papers/faculty/year, or three times the rate for physical science faculty at undergraduate institutions (Research Corporation 2001).

A major venue for the success of the MERCURY has been the national conference, which is open to undergraduates and faculty from all institutions. The conferences usually had an average attendance of 85-90. The 2014 conference had 110 participants, and the 2015 conference had 76. Many faculty and students from institutions that were not part of the MERCURY consortium have attended the conference and benefited from networking and discussions with other faculty and students working in computational chemistry. In 2013, the undergraduate students presented 53 posters, 29 of which were presented by female students. In 2014, the students presented 69 posters, 29 by female students. In 2015, the 14th annual conference, the students presented 47 posters, 23 by female students. Students benefited from the opportunity to present their work to experts. Faculty benefited from the networking opportunities.

\section{Fifth Grant Period, 2016-2019}

The success of the consortium, both in terms of research productivity and student outcomes, including inclusive excellence in each of the institutional research groups and at annual conferences, led to a more dramatic expansion of the consortium for the fifth NSF MRI grant proposal in 2016. MERCURY was expanded to include 27 researchers at 24 institutions. Padgett left the consortium, and 11 faculty members were added: George Barnes (Siena College), Nick Bodkelheide (Colby College), Chrystal Bruce (John Carroll University), JiaJia Dong (Bucknell University), Dmytro Kosenkov (Monmouth University), Ashley McDonald (California Polytechnic State University-San Obispo), Bill Miller (Truman State University), Juan Navea (Skidmore College), Joshua Schrier (Haverford College), Isaiah Sumner (James Madison University), and Mychel Varner (Iona College). Varner had been Nagan's first undergraduate research student. Miller was an undergraduate in the Nagan lab and also a postdoctoral fellow with Parish, as his goal was to teach and work with undergraduate research students at a primarily undergraduate institution. A total of $\$ 320,000$ was requested for the addition of high-performance computers, and $\$ 225,000$ was received to expand the Linux cluster (award CHE 1626238).

The grant proposal noted that MERCURY faculty were particularly well funded to support summer research. The senior members of the group had five NSF RUI grants and other grants from Research Corporation, ACS/PRF, and other NSF programs (7 total), as well as grants from foundations that combined teaching with research. In total, 15 MERCURY faculty had 25 grants totaling \$8,399,802 listed as current support.

The National Science Foundation receives about 50,000 proposals for funding every year. The foundation distinguishes among so many worthy proposals through a merit review process that incorporates two criteria: intellectual merit and broader impacts. These criteria were met by the MERCURY faculty as described in the next paragraphs.

In the category of intellectual merit, overall, since 2001 when the first MRI grant was funded, the MERCURY investigators had published 234 papers, including 2 in Science, 2 in Angewandte Chemie, International Edition, 10 in JACS, and 2 in PNAS. There were 44 publications during the first MRI grant period, 49 during the second, 62 during the third, and 79 during the fourth. The peerreviewed publication rate was 1.7 papers/faculty/year, which was 3.4 times the rate of physical science faculty at undergraduate institutions (Research Corporation 2001).

The consortium also had significant broader impacts over the same time period. Faculty worked with 563 students on research projects. Without double-counting female minority students, this included a total of 422 female and minority students, or 75 percent of the total. Approximately half of graduates went on to graduate school for the purpose of obtaining advanced degrees in STEM fields, approximately two-thirds of whom were female and/or minority 
FIGURE 4. The 16th Annual MERCURY Conference on Computational Chemistry, July 20-23, 2017, Furman University, Greenville, SC

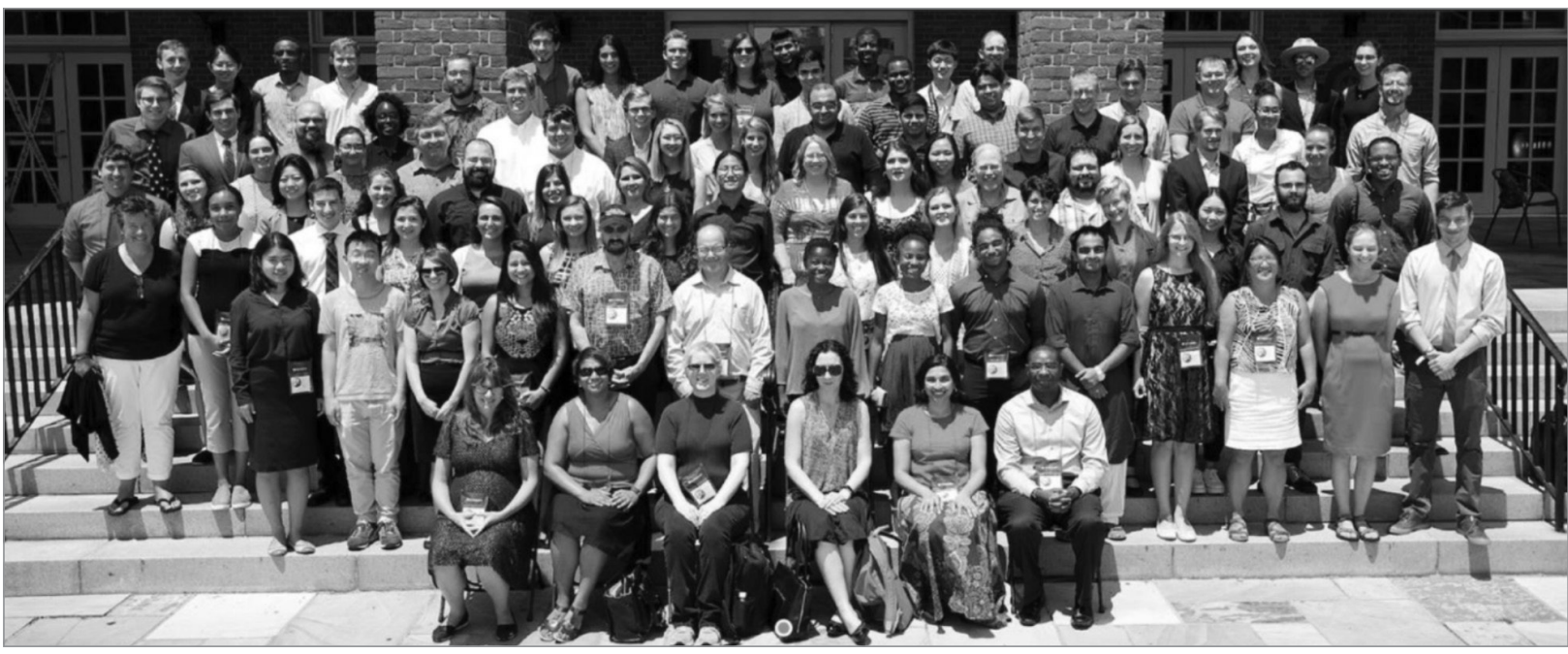

Front row (from left to right): Keynote speakers Eva Zurek (University at Buffalo-SUNY), Revati Kumar (Louisiana State University), Theresa Windus (Iowa State University), Katrina Lexa (Denali Therapeutics), Nandini Ananth (Cornell University), and Valentino Cooper (Oak Ridge National Laboratory).

students. Since the start of the MERCURY consortium students mentored by MERCURY faculty had won more than 50 national awards, including 1 Rhodes, 10 Fulbright, 18 Goldwater, and 2 Gates Cambridge Scholarships, as well as more than 15 national graduate fellowships (NSF, NDSEG, NASA). There had been more than 1,200 attendees at the 14 MERCURY conferences, along with 87 speakers, 45 of whom had been female or from an underrepresented group.

Clearly, success begets success. An association of committed faculty has developed. Faculty members thrive, feeding off the group's energy and mutual commitment to undergraduate research and inclusive excellence. The annual conference has provided a great venue for mentoring and sharing tips about how to stay as productive as possible (e.g., write something related to ongoing research every day, begin writing before heading into a break to generate momentum, and always resubmit a grant proposal that is not funded on the first attempt). There was a need for a more formal arrangement as the consortium grew in size, and this led to mentoring groups of four to six faculty members who check in with each other on a regular basis via a phone conference. Bruce continues to track progress and adherence to this proposal.

At the end of July 2016, the 15th MERCURY Conference on Computational Chemistry was held, with 6 invited speakers. Students presented 64 posters at this conference. There was a total of 120 attendees at this conference, the last at Bucknell University, as the author moved to Furman University (SC) that summer to serve as provost. In July 2017, the 16th annual conference was held, with invited speakers Theresa Windus (Iowa State University), Valentino Cooper (Oak Ridge National Laboratory), Eva Zurek (University at Buffalo-SUNY), Revati Kumar (Louisiana State University), Nandini Ananth (Cornell University), and Katrina Lexa (Denali Therapeutics; see Figure 4). Cooper was a Vassar undergraduate research student with Gomez, and Lexa was an undergraduate research student who worked with the author. Students presented 46 posters at the 2017 conference. There were 92 attendees at this first conference on the Furman University campus. Immediately after the conference, Molecular Sciences Software Institute (MolSSI) members Windus, Paul Nerenberg (California State University, Los Angeles), and Lee-Ping Wang (University of California, Davis) presented a workshop for 40 participants that covered the basics of Python, MD trajectory analysis and visualization, GIT, and GITHUB.

During the 2016-2017 academic year, the 27 MERCURY faculty mentored 146 undergraduate students, 4 high school students, 1 research scientist, 1 postdoctoral fellow, and 1 postbaccalaureate student. The 146 undergraduate students included 60 males and 86 females. Fifty-two of the students were students of color. Overall, the number of underrepresented students (all females plus male students of color) was 111. Thus, 76 percent of the students working with the MERCURY faculty were diverse (the remaining 24 percent were white males). The students of color included 13 African American males, 9 African American females, 7 Asian males, 14 Asian females, 4 Hispanic/Latino males, $4 \mathrm{Hispanic/Latina} \mathrm{females,} \mathrm{and}$ 1 male Pacific Islander. Additional students included 35 white males and 59 white females. This development of human resources was significant, as each undergraduate 
research student gained significant exposure to the scientific research process and each participant developed valuable computer skills through exposure to the Linux operating system, scripting languages, and procedures for accessing remote computing resources. Additionally, undergraduate participants gained a better understanding of quantum chemical theory and its applications. The MERCURY faculty published 1 book, 3 commentaries on undergraduate research, and 37 peer-reviewed papers in 2016-2017, including 1 paper in Science, 1 in Nature, 1 in the Journal of the American Chemical Society, and 1 in Chemical Society Reviews.

Bodkelheide left the consortium in 2017, and in 2017-2018 Heidi Hendrickson (Lafayette College), He Kedan (Eastern Connecticut State University), Aurelia Ball (Skidmore College), and Joseph Baker (the College of New Jersey) were added. In 2018, Zimmer, one of the original senior investigators, retired from the consortium. Eggimann and Gao left the consortium as well. Currently there are 27 faculty at 24 institutions. Many of the faculty have made career moves. Nagan moved from Truman State to Adelphi University, and is now at Stony Brook University-SUNY. Patterson also moved from Truman State to Stony Brook University-SUNY. Both of their research groups are 100 percent undergraduate, so they have stayed in MERCURY. Shepherd moved from Westminster College to St. Edward's University, then to Moravian College, and is now at Franklin and Marshall College. Joshua Schrier left Haverford College for an endowed professorship at Fordham University.

During the 2017-2018 period, 1 technical book, 4 book chapters, and 46 peer-reviewed papers in the scientific literature, including a paper in Nature Reviews Chemistry, were published. The 46 peer-reviewed papers by the 27 MERCURY faculty yielded 1.7 papers per faculty member, or 3.4 times the average publication rate for physical scientists (Research Corporation 2001). Consortium members often are asked by faculty at research universities to collaborate (Rovnyak and Shields 2018). Students presented more than 150 talks and poster presentations at conferences and other venues. The consortium hosted the 17th MERCURY Conference on Computational Chemistry with invited speakers Chris Cramer (University of Minnesota), Saryu Fensin (Los Alamos National Laboratory), Laura Gagliardi (University of Minnesota), Rigoberto Hernandez (Johns Hopkins University), Bethany Kormos (Pfizer), and Carlos Simmerling (Stony Brook UniversitySUNY). Fensin was an undergraduate research student with Gomez and attended a MERCURY conference as an undergraduate. The 70 students in attendance presented 61 posters at the 2018 conference, and there were a total of 107 attendees at this second conference on the Furman University campus. Prior to the conference, there was a two-day MolSSI coding workshop. The workshop was presented by MolSSI members Windus, Nerenberg, and Ball. There were 25 attendees at the workshop.

Conferences are routinely evaluated. Evaluations of the 2018 MERCURY conference returned overwhelmingly positive feedback. The keynote speakers were received well and scored 4.47 out of 5 on the postconference survey. The poster sessions were reported by the undergraduate students to be the highlight of the conference experience, as they shared their work with peers and professors and made professional contacts, and were rated 4.18/5. Scheduling and format were rated 4.50/5, and accommodations were rated $4.56 / 5$. The conference had an overall average rating of $4.43 / 5$, and attendance is expected to continue to increase. The MolSSI workshop also was received very well. It provided the first programming experience for most of the attending students, who were thrilled to learn how computational chemists approach coding. The MolSSI workshop also received high ratings.

In all, 134 undergraduate students, 1 high school student, 1 research scientist, 2 postdoctoral fellows, and 1 postbaccalaureate student were mentored in 2017-2018. Of the 134 undergraduate students in the labs, 64 returned from the previous year and 70 were new. Of the 70 new students, 35 were male, and 35 were female. Of the 35 male students, 21 , or 60 percent, were students of color. Of the 35 female students, 26, or 74 percent, were students of color. The total number of students of color was 47 , or 67 percent. Overall, the number of underrepresented students (all females plus male students of color) was 56, or 80 percent. The students of color included 9 Asian males, 6 Hispanic/Latino males, 6 black males, 16 Asian females, 8 Hispanic/Latina females, 1 black female, and 1 Pacific Islander female. Also participating were 14 white males and 9 white females.

During the 2018-2019 academic year, 196 undergraduate students, 4 high school students, 3 master's students, 1 postbaccalaureate fellow, and 1 postdoctoral fellow received mentoring. Of the 196 undergraduates, 70 were new students. Of the 70 new students, 38 were female, and 11 of these students were women of color. Of the 32 males, 7 were men of color. Thus, overall, 45 of the new students (64 percent) were students of color. The students of color included 3 Asian females, 3 black females, 4 Hispanic/Latina females, 1 mixed-race female, 2 Asian males, 2 black males, and 3 Hispanic/Latino males. The 18th MERCURY conference hosted speakers Melissa Landon (Schrodinger), Anne McCoy (University of Washington), Nick Mayhall (Virginia Tech), Frank Pickard (Pfizer), Adrian Roitberg (University of Florida), and Sapna Sarupria (Clemson University). Pickard is a MERCURY alum. The 59 undergraduates in attendance made 59 poster presentations and were joined by 25 faculty and the 6 keynote speakers, for a total of 90 participants at the meeting.

12 Scholarship and Practice of Undergraduate Research 
Prior to the conference, there was a two-day MolSSI coding workshop. The workshop was presented by MolSSI members Lee-Ping Wang (University of California, Davis), Paul Nerenberg (California State University, Los Angeles), Olaseni Sode (University of Chicago); and Ashley Ringer McDonald (California Polytechnic State University-San Luis Obispo). There were 27 attendees at the workshop. The MERCURY faculty published 6 ACS Symposium book chapters and 40 papers during this time, including 1 in Nature, 2 in the Journal of the American Chemical Society, 1 in Angewandte Chemie, International Edition, and 1 in the Proceedings of the National Academy of Sciences USA. In addition, the Journal of Physical Chemistry published a virtual issue of excellent research previously published in the journal by faculty working at PUIs, and Joshua Schrier cowrote the editorial for this issue (see Londergan and Schrier 2019). The issue itself featured research by six MERCURY faculty: Barnes, Donald, Navea, Parish, Phillips, and Shields.

Overall, during the 2016-2019 grant period there were 325 undergraduates, and 71 percent were female and/or students of color. In addition, 9 high school students, 2 postbaccalaureate fellows, 3 master's students, 2 postdoctoral researchers, and 1 staff research scientist worked with the MERCURY investigators. A total of 123 peer-reviewed papers, or 1.52 papers/faculty/year, 2 technical books, and 11 book chapters were published. There were four successful conferences that averaged 102 attendees and averaged 52.5 undergraduate poster presentations. Of the 24 speakers, 16 were female and/or faculty of color.

\section{Consortium Goals, 2001-2019}

When the consortium began in 2001, the goal was to acquire a supercomputer that would allow training of undergraduates in computational chemistry and achievement of excellent research results. There were diverse research interests that required computational systems that would allow simulations to run with a variety of different software. The aim was to excite and inspire students with real research projects, so that many of them would go on to graduate work or become citizens with a deeper understanding of what research was and how it worked. There was a need for technical support for the computer system and a need to assure equity of computer time. Faculty diversity was a goal from the beginning. The idea was to create a Northeast consortium that would meet for an annual conference and share ideas as well as learn from and network with faculty and professionals from research universities, industry, and government laboratories. After the first grant period, added resources allowed work with more undergraduate research groups and expansion to a national level. The annual conference was the most valuable asset of the consortium, and after the first grant period, funding support for this continued. The mentoring, networking, and inspiring activities provided by the annual conferences were highly valued by faculty. Faculty invited to join MERCURY were motivated to have active and diverse research groups, and deans and provosts were requested to provide funding support for meeting attendance. Faculty mentoring groups met during the year by teleconference. As time went on, speakers received guidance on constructing their talks for the maximum benefit of the undergraduate audience. Keynote speeches provided in-depth explanation and discussion of motivation for a study, the techniques used, and the results. Undergraduate attendees moved from merely listening to the presentations to asking thoughtful questions of the presenters. Overall, the main goals of the consortium have not changed, and the program has achieved success beyond all expectations.

\section{Faculty Career Impacts, 2001-2019}

Participation in the consortium has had substantial effects on the careers of MERCURY faculty, who have received tenure and have been steadily promoted. Below are brief profiles of four members that include quotes they have provided for this article.

Parish, a founding member of MERCURY, received the 2005 Henry Dreyfus Teacher-Scholar Award, the 2011 Stan Israel Award for Advancing Diversity in the Chemical Sciences, the CUR-Goldwater Scholars Faculty Mentor Award, and the 2019 American Chemical Society Award for Research at an Undergraduate Institution. She is an ACS Fellow (2015) and was named the Floyd D. and Elisabeth S. Gottwald Professor in 2009. Gomez, another founding member of MERCURY, received the Meribeth E. Camerson Faculty Award for Scholarship in 2015 for her work on proton conduction in perovskite crystals and was named the Elizabeth Page Greenawalt Professor of Chemistry in 2017. She leads the Passport to Chemistry Adventure program for children at Mount Holyoke College. Phillips (University of Wisconsin-Eau Claire, or UWEC), joined MERCURY in 2012. He is one of two members of MERCURY who leads joint experimental/computational chemistry programs. Phillips received the UWEC College of Arts and Sciences Career Teaching Excellence Award in 2013 and the UWEC Excellence in Mentoring Research, Scholarship, or Creative Activity Award in 2015. He recently became chair of his department. Baker, an assistant professor at the College of New Jersey, joined MERCURY in 2018. Baker has received three grants from NSF (RUI, MRI, and collaborative).

Parish states:

My involvement in the MERCURY consortium has allowed my undergraduates the opportunity to be part of a larger community of like-minded, goal-oriented scholars. They have had numerous opportunities to present their results at MERCURY and these experiences have encouraged them to present at other national 
and international meetings. The camaraderie and intellectual exchange that occurs via the MERCURY consortium has also elevated my own career by allowing me the opportunity to discuss best practices in teaching, research and mentoring, as well as career goals and computational infrastructure and configuration.

Gomez observes:

The MERCURY consortium has not only been helpful in connecting students and building their self-esteem and professional outlook but has also helped me feel more connected to faculty facing the same challenges and motivating me to continue to work hard mentoring and doing research with undergraduates. As we have gained experience, our goals now include the mentoring of newer faculty. The specifics of how we can best mentor our newest faculty are still an evolving work.

Phillips states: "The MERCURY conference is the most effective conference I have ever taken my students to, both in terms of learning experiences and networking opportunities for them."

Baker states:

The MERCURY Consortium has provided me-the sole computational chemist at the College of New Jersey - with an opportunity to belong to a community of colleagues at other PUIs to discuss pedagogy, research, and professional development. This has made me a better mentor and teacher-scholar for my own students. Additionally, I have frequently brought students to the MERCURY Consortium meeting as their first experience presenting on their research. The friendly atmosphere of the meeting has been transformative for my students with regards to building their confidence [in] discussing their work.

\section{Conclusions}

The MERCURY consortium has been an outstanding program that has contributed greatly to the development of scientifically trained undergraduates, with a particular focus on diversity and inclusion. Table 1 summarizes the key factors of this successful consortium. The very nature of the consortium emphasizes diversity, with 13 female faculty and 9 faculty of color out of 27 total (18 of 27 , or two-thirds, without double-counting female faculty of color). The peer-reviewed publication rate of MERCURY faculty is 1.7 papers/faculty/year, which is 3.4 times the rate of physical science faculty at primarily undergraduate institutions (Research Corporation 2001). From 2001, when the first NSF MRI grant was funded, through summer 2019, MERCURY investigators have published 357 papers, including 2 in Chemical Society Reviews, 1 in Chemical Reviews, 1 in Nature Reviews Chemistry, 3 in Science, 2 in Nature, 3 in Angewandte Chemie, International Edition, 13 in JACS, and 3 in PNAS. There have been 888 students who worked on research projects. Seventy-five percent of the undergraduate research students have been either females or male students of color. Approximately half of graduates have gone on to attend graduate school for the purpose of obtaining advanced degrees in STEM fields. Of these, approximately two-thirds are female and/or students of color. Since the start of the MERCURY consortium, students mentored by MERCURY faculty have won more than 50 national awards, including 1 Rhodes, 10 Fulbright, 21 Goldwater, and 2 Gates Cambridge Scholarships and more than 20 national graduate fellowships (NIH, NASA, NDSEG, NSF). There have been more than 1,600 attendees at the 18 MERCURY conferences and 111 speakers, 61 of whom have been female and/or faculty of color (see MERCURY Consortium n.d.).

TABLE 1. Key Factors Contributing to Success of the MERCURY Consortium

\begin{tabular}{|l|l|l|}
\hline Faculty & Conference & Leadership \\
\hline $\begin{array}{l}\text { Commitment to research excellence in } \\
\text { computational chemistry }\end{array}$ & $\begin{array}{l}\text { Featured poster session solely for } \\
\text { undergraduates }\end{array}$ & $\begin{array}{l}\text { Commitment to diversity and inclusive } \\
\text { excellence }\end{array}$ \\
\hline Commitment to undergraduate research & $\begin{array}{l}\text { Featured one- to two-minute oral } \\
\text { presentations followed by poster session }\end{array}$ & $\begin{array}{l}\text { Development and recruitment of like-minded } \\
\text { mentors to consortium }\end{array}$ \\
\hline $\begin{array}{l}\text { Commitment to diversity and inclusion } \\
\text { undergraduates }\end{array}$ & $\begin{array}{l}\text { Principal investigators' meeting for all } \\
\text { MERCURY faculty }\end{array}$ & Recruitment of diverse faculty to consortium \\
\hline $\begin{array}{l}\text { Skill in running research groups for students } \\
\text { with different backgrounds and skill levels }\end{array}$ & $\begin{array}{l}\text { Diverse and inclusive speakers (61 of } 111 \\
\text { speakers female and/or faculty members } \\
\text { of color) }\end{array}$ & $\begin{array}{l}\text { Commitment to assessment and } \\
\text { transparency; sharing of all outcomes } \\
\text { with current and potential new members }\end{array}$ \\
\hline Role models for diversity and inclusion & Attendees modeling inclusive excellence & Leadership by example \\
\hline
\end{tabular}

14 Scholarship and Practice of Undergraduate Research 
This program can be a model for other topic-based consortia and for increasing the amount of high-quality mentored undergraduate research in any discipline of the academy. Key factors include forming a collaboration of like-minded faculty who are committed to diversity and inclusion, high-quality research, and working with undergraduates on research projects. Additionally, a mix of faculty colleagues at different career stages allows for the sharing of problems, successes, and suggestions, improving each faculty member's ability to be a successful teacher-scholar. A key component of program success is an annual meeting, at which experts talk both with students at their poster sessions and with faculty attendees, increasing the value of the meeting for all. In addition, the meeting provides a dedicated time for MERCURY faculty to mentor and advise each other. Students from one research group see their own work in a larger context and learn from other research groups about the problems they are trying to solve and their approaches to solving them. Students also learn from other faculty and invited speakers who talk to them at their poster sessions. Representation of female faculty and faculty of color is considered carefully in choosing the speakers. Students see the speakers and the other faculty in attendance as role models. Finally, annual evaluations required by NSF focus the entire MERCURY faculty on student outcomes and research results and motivate the next year's efforts. An annual evaluation, shared with all faculty participants, is essential to keeping the group focused on its own goals as a consortium.

\section{Acknowledgments}

The research discussed was supported by the following grants: NSF CHE-0116435, NSF CHE-0521063, NSF CHE-0821581, NSF CHE-1229354, and NSF CHE1626238.

\section{References}

Kinnel, Robin B., Adam W. Van Wynsberghe, Ian J. Rosenstein, Karen S. Brewer, Myriam Cotten, George C. Shields, Charles J. Borton, et al. 2013. "A Departmental Focus on High Impact Undergraduate Research Experiences.” In Developing and Maintaining a Successful Undergraduate Research Program, ed. Timothy W. Chapp and Mark A. Benvenuto, ACS Symposium Series, vol. 1156, 5-22. Washington, DC: American Chemical Society. doi: 10.1021/bk-2013-1156.ch002

Londergan, Casey, and Joshua Schrier. 2019. "Research in Physical Chemistry at Primarily Undergraduate Institutions.” Journal of Physical Chemistry A 123: 3239-3240. doi: 10.1021/acs. jpca.9b02334

MERCURY Consortium. n.d. http://mercuryconsortium.org/

Research Corporation. 2001. Academic Excellence: The Sourcebook; A Study of the Role of Research in the Natural Sciences at Undergraduate Institutions. Tucson, AZ: Research Corporation.

Rovnyak, David, and George C. Shields. 2018. "A Roadmap to Successful Collaborations between Primarily Undergraduate Institutions and Research Institutions." In Credit Where Credit Is Due: Respecting Authorship and Intellectual Property, ed. Patricia A. Mabrouk and Judith N. Currano, ACS Symposium Series, vol. 1291, 105-127. Washington, DC: American Chemical Society. doi: 10.1021/bk-2018-1291.ch011

Shields, George C. 2002. "The Benefits of Forming a Consortium for an NSF-MRI Proposal." CUR Quarterly 23(2): 80-81.

Shields, George C., Delana A. Gajdosik-Nivens, and Traci Ness. 2017. "Using Early Introduction to Research to Increase STEM Majors: A Tale of Two Colleges, One Small Highly Selective Private and One Non-Selective Regional Public." In Educational and Outreach Projects from the Cottrell Scholars Collaborative, ed. Rory Waterman and Andrew Feig, ACS Symposium Series, vol. 1248, 107-119. Washington, DC: American Chemical Society. doi: 10.1021/bk-2017-1248.ch007

\section{George C. Shields}

Furman University, George.shields@furman.edu

George C. Shields is a professor of chemistry and director of the Molecular Education and Research Consortium in Undergraduate Computational Chemistry (MERCURY) at Furman University. He has mentored 118 undergraduates and has published 56 papers with 57 undergraduates working in his research group since 1991. His 87 articles and reviews in the Web of Science database have been cited more than 5,000 times. He has received more than $\$ 5.6$ million in external research grant support for his work, and his students have received 34 national awards, including 4 Fulbright and 9 Goldwater Scholarships and 7 graduate fellowships. He is a Fellow of the American Association for the Advancement of Science, the recipient of the American Chemical Society's 2015 Award for Research at an Undergraduate Institution, and the recipient of the Research Corporation for Science Advancement's 2018 Transformational Research and Excellence in Education (TREE) Award. 